\title{
Survey and Research on Chinese Sport Industry and Financial Benefit based on Mathematical Modelling and Game Theory
}

\author{
Yingwei Zhao ${ }^{1, a^{*}}$, Lina Zhu, a \\ ${ }^{1}$ Qingdao University of Science \& Technology, Qingdao 261000, China \\ azhaoyingwei666@126.com
}

\begin{abstract}
Keywords: Sport Industry; Financial Benefit; Game Theory; Modelling and Simulation.
\end{abstract}
\begin{abstract}
With the rapid and irreversible development of sport science and related techniques, the combination of sport management with developed financial benefit theory is urgently needed. In this paper, we conduct survey and research on Chinese sport industry and financial benefit based on mathematical modelling and game theory. Firstly, we introduce the chief concepts and principles of Chinese sport industry in the introduction section. Later, through mathematical modelling and game theory we conduct building ad implementing our methodology in the second section. Our research indicates that marketing process takes the ability to improve the optimized allocation of sports resources, and take the market as the guide to provide sports products or services, to strengthen the sports industry in our country, which makes it really become a new growth point of national economy. In the final section, we conclude and summary the research with optimized suggestions.
\end{abstract}

\section{Introduction}

China is a unified multi-ethnic country. Our country is in a special historical stage of economic transformation and institutional change, sports enterprise to obtain sustainable development, the need for the overall and deep reform, reform and industrialization is the inevitable choice [1-3]. Marketing process takes the ability to improve the optimized allocation of sports resources, and take the market as the guide to provide sports products or services, to strengthen the sports industry in our country, which makes it really become a new growth point of national economy. As a result, the sports industry should not only serve the spiritual needs of people, also want to pursue profit maximization, in order to realize our country sports industry from a planned pattern to the smooth transition of the market model, need to deepen the understanding of sports industry and economic properties [4-5].

Marketing refers to the market in the basic regulatory role in the allocation of resources. Marketization of sports industry means the relaxation of sports management department run sports industry the main body of administrative controls, to "market mechanism is given priority to, administrative intervention is complementary" as the basic principle of regulating the sports industry [6-7]. Specifically, in order to realize the collective honor, sports management department plays a leading role, but the problems of low efficiency and lack of oversight, influence the development of for-profit and nonprofit sports organization, it will contain the improvement of sports competition, fundamentally hinder the establishment of the collective sense of honor; To achieve economic benefits, the non-profit sports organizations are playing a key important, but the existence of excessive pursuit self-interest, and the excessive intervention of sports management department and administrative control, will reduce the profit level non-profit sports organizations; To achieve the national fitness, the nonprofit sports organization plays a decisive role, but there exists a social awareness is not high, insufficient funding and legal protection does not reach the designated position, on the one hand to be induced through the prosperity and development of the non-profit sports organizations, to drive the public fitness leisure consciousness, on the other hand need to sports management department to provide funding support and legal protection [8]. 
To deal with the mentioned issues, in this research we conduct survey and theoretical analysis on the topic of Chinese sport industry and financial benefit based on mathematical modelling and game theory. The introduced game theory is to balance the factors which may influence the general and overall performance of sport industry management.

\section{Our Proposed Methodology}

General Status of Traditional Sport Industry in China. About national traditional sports industry classification, the researchers have not reached an agreement with judgment. Some scholars agree idea that all industries, make traditional sporting goods and service can be production, exchange, consumed and in order to meet the increasingly sporting demands can be divided into the industry. In the process of marketization of sports industry, sports management department as a "face" of the government, the goal must be diversified, various political interests, social benefits and economic benefits of interweave together, which makes it hard for sports management department to real interests of all kinds of folk sports organizations, and from different interest subjects, unavoidably cause sports management department and the contradiction of folk sports organizations, to coordinate the interests of all parties relationship. Football association, for example, excessive concentration of power, reject market, mandatory and the mandatory administrative measures to manage professional football development, especially with the property of the administrative intervention to the club sponsors industry make a restrictive provisions, such as damage the interests of the club's market. Under the traditional planned economy system, the sports management department has the problem of unclear role positioning, control the sports resources in their own hands, a lot of social capital involved in the sports industry. The radical reform of the sports industry is to take the market to promote the path, giving substantial autonomy of folk sports organizations in power, to relax administrative functions and powers of the sports industry. To break the deadlock, therefore, need to weigh the gain and loss, of folk sports organizations in sports management departments and to find common interests. The general pattern of the sport industry could be visually described in the figure 1 .

\begin{tabular}{|c|c|}
\hline $\begin{array}{l}\text { First class } \\
\text { name }\end{array}$ & Second class name \\
\hline \multirow{4}{*}{$\begin{array}{l}\text { Nation } \\
\text { traditional } \\
\text { sports } \\
\text { preliminary } \\
\text { industry }\end{array}$} & $\begin{array}{l}\text { Nation traditional sports competition and } \\
\text { performance industry }\end{array}$ \\
\hline & $\begin{array}{l}\text { Nation traditional sports fitness and } \\
\text { entertainment industry }\end{array}$ \\
\hline & $\begin{array}{l}\text { Nation traditional sports training and consultant } \\
\text { industry }\end{array}$ \\
\hline & $\begin{array}{l}\text { Nation traditional sports assets operation } \\
\text { industry }\end{array}$ \\
\hline \multirow{6}{*}{$\begin{array}{l}\text { Nation } \\
\text { traditional } \\
\text { sports attached } \\
\text { industry }\end{array}$} & $\begin{array}{lcc}\text { Nation traditional sports } & \text { products } \\
\text { manufacturing industry } & & \end{array}$ \\
\hline & $\begin{array}{l}\text { Nation traditional sports clothing and souvenir } \\
\text { industry }\end{array}$ \\
\hline & Nation traditional sports architectural industry \\
\hline & Nation traditional sports advertisement industry \\
\hline & $\begin{array}{lccc}\text { Nation traditional } & \text { sports } & \text { equipment } \\
\text { manufacturing industry } & & \\
\end{array}$ \\
\hline & Nation traditional sports consumption industry \\
\hline
\end{tabular}

Figure 1. General pattern of sport industry in China

Assumptions before Modeling. Marketization of sports industry in the game process involves three categories of stakeholders: one is the country and the sports administrative departments at all levels, including the state general administration of sports, the sports management center (association), the local sports management department with administrative functions and powers of regulators, in some 
sense, the administrative department for physical culture and sports is similar to the Chinese government agency direct interest in the field of sports management representative; it is non-profit sports organizations, including sporting events planning enterprise, enterprise product design, product research and development enterprises, enterprises in sports products, sports products sales companies, consulting companies, brokerage companies, professional sports clubs, sports training, sports media organizations, sports performance enterprise, etc. In order to realize the profit maximization as the fundamental goal, independent, self-sustaining sports organizations; Third, besides have official sports management department of various non-profit sports organizations, including all kinds of sports fans association (football lovers association, badminton lovers association, etc.), fans association, folk sports community organizations, sports volunteer organizations, charitable organizations, sports scientific research units, colleges and universities has the public sports organizations. In the process of marketization of sports industry, not only need policy support and guide the sports management department, and in need of for-profit and non-profit sports organizations and other social forces to participate and cooperate, can we truly achieve the purpose of marketization of sports industry development in our country, comprehensive drive all kinds of sports organizations and the vigorous development of various undertakings of physical culture and sports [9-10].

Game Theory Combined Model. In our model, we choose game theory as the basic model descriptor. For sports management department, the non-profit sports organizations and non-profit organizations, select the "support" or "participation" strategy is superior to choose "not support" or "not to participate in" strategy, therefore, (support, participation, participation) is the optimal strategy choice of the game parties. However, because the game side of bounded rationality, they do not know the optimal strategy, also is unable to find the optimal equilibrium in every game, so the best strategy is through imitation and improved for a long time, has become a stable strategy, this strategy is called evolutionary stable strategy. As a special mode of production and consumption of culture and the role of spirit, only the way of the sports industry can let it shine. This is an important subject how to potential resources and factors of production into real economic advantage, give appropriate statistics and evaluation of national traditional sports industrialization and the development of national traditional sports industry in a vicious circle. The corresponding evolution path diagram is shown in figure 2 .

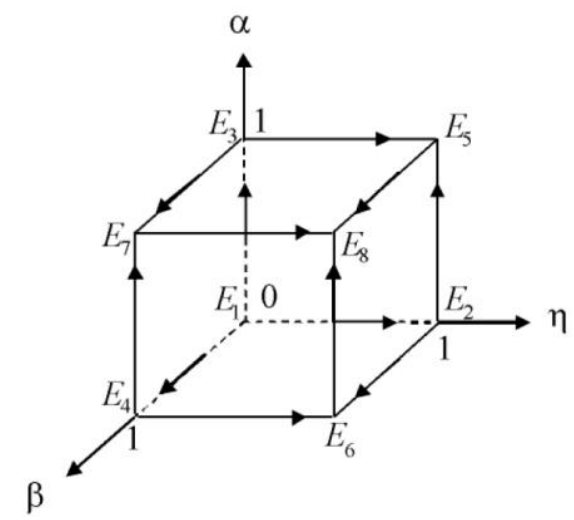

Figure 2. The corresponding evolution path diagram

According to the evolution path diagram, we could derive the sports management departments, for-profit and nonprofit organization replicated dynamic equation in the equation 1. 


$$
\left\{\begin{array}{c}
F(\eta)=\frac{d \eta}{d t}=\eta(1-\eta)\left(\pi_{G 1}-C_{G 1}-\pi_{G 2}+C_{G 2}\right) \\
F(\alpha)=\frac{d \alpha}{d t}=\alpha(1-\alpha)\left(\pi_{P 1}-C_{P 1}-\pi_{P 2}+C_{P 2}\right) \\
F(\beta)=\frac{d \beta}{d t}=\beta(1-\beta)\left(\pi_{n p 1}-C_{n p 1}-\pi_{n p 2}+C_{n p 2}\right)
\end{array}\right.
$$

We could find out eight balance points from the corresponding equation. However, the eight points are not necessarily evolutionary stable strategy this is because a steady state must have robustness to small perturbations can be referred to as the evolutionary stable strategy. Using Lyapunov theorem to judgment here will help us revise the equation. From the result of the equation, we could make the following conclusions. Sports management departments, for-profit and nonprofit organization respectively take "support" "in" "participation" is the evolutionary stable strategy game. Support for sports management department, the sports industry market namely quicken the steps of sports industry legislation, broaden the financing mechanism of the sports industry, gives a for-profit and nonprofit sports organization fully free trade space, implementing supervision and regulation functions, stimulate the enthusiasm of market main body and energy, for the healthy development of sports industry is an important responsibility for "escort". For non-profit sports organizations, and actively participate in the marketization of sports industry, "baptism" to the fierce market competition, the rich market experience and lessons, a comprehensive understanding of consumer needs and market trend, get more consumer recognition, and to enhance the brand awareness is very important. For the non-profit sports organizations, to participate in the sports industry market, to adapt to the trend of the development of mass sports, the national fitness, and the integration of the new market idea, conveying more professional sports talents for the society, so as to obtain more extensive mass base and attention, have higher social reputation. Later, the marketization of sports industry is not to be denied any sports administrative department of the administrative functions. There is a one-sided view market is the most effective means of resource allocation, can completely replace the governmental administrative regulation. Actually otherwise, when severe asymmetric information situation, the market itself cannot effectively satisfy the public interest, government departments through appropriate administrative intervention is needed at this time to maintain the normal order of market transactions. The revised equation could be formulated as the following expression:

$$
J=\left|\begin{array}{lll}
\frac{\partial F(\eta)}{\partial \eta} & \frac{\partial F(\eta)}{\partial \alpha} & \frac{\partial F(\eta)}{\partial \beta} \\
\frac{\partial F(\alpha)}{\partial \eta} & \frac{\partial F(\alpha)}{\partial \alpha} & \frac{\partial F(\alpha)}{\partial \beta} \\
\frac{\partial F(\beta)}{\partial \eta} & \frac{\partial F(\beta)}{\partial \alpha} & \frac{\partial F(\beta)}{\partial \beta}
\end{array}\right|
$$

According to the equation 2, we could make the conclusion that: the sports industry is different from other industries, because sports products or services, some belong to private products, such as sports venues, can through the market means to improve the efficiency of product supply; Some sports products or services are belong to public products has a strong positive externalities, such as public sports venues, easily lead to excessive unfair supply, supply and demand, the market mechanism is a failure, it will need sports administrative intervention measures, the administrative department to make up for the market is invalid. Therefore, in the process of marketization of sports industry, both should attach great importance to the spontaneous regulation of market, also cannot ignore the administrative functions of sports management department, so as to avoid the "market failure" and "government failure" and other bad phenomenon. 


\section{Summary and Conclusion}

Our country is in a special historical stage of economic transformation and institutional change, sports enterprise to obtain sustainable development, the need for the overall and deep reform, reform and industrialization is the inevitable choice. With the absence of scientific theory guidance systems and proper statistical evaluations. These defects cause it can't give an accurate quantitative description of the economic value and status in the industry of national traditional sports industry. On the other hand, the influence to recognize and accept national traditional sports industry mainstream economists. From our research, we provide the following suggestions for referencing. In particular, need to shift the administrative concept and management function, sports management department in accordance with the laws of the market economy as the principle, using the administrative power reasonably, continually establish and improve the corresponding policies and regulations support the marketization of sports industry, build system of sports property rights, investment of time and money to cultivate sports products market, sports competition market, financial markets, technology markets, sports performance, sports lottery market, sports market consulting, sports tourism market, etc., for the sports industry market operation to create a good institutional environment and legal environment. In conclusion, with the proposed game theory assisted model, we could manage and balance the Chinese sport industry more appropriately.

\section{References}

[1] Ko, Y., \& Pastore, D. (2005). A hierarchical model of service quality for the recreational sport industry. Sport Marketing Quarterly 2005 Vol. 14 No. 2 pp. 84-97.

[2] Milano, M., \& Chelladurai, P. (2011). Gross domestic sport product: the size of the sport industry in the united states. Journal of Sport Management, 25, 1, 24-35.

[3] Mei-li, W., Chui-hui, K., \& Bao-guo, R. (2005). The opportunity and challenge:university sport industry after china's entry into wto. Journal of Beijing University of Physical Education.

[4] Changqiu, L., Jing, L., \& Institute, L. (2014). On legislative protection of china's sport industry. Journal of Chengdu University of Technology(Social Sciences).

[5] Lei, W., \& Hu-ke, S. (2014). Leading sport industry development by technology innovation: patent literature and information analysis on nike inc. patents. Journal of Beijing Sport University.

[6] Qian, L., \& University, C. S. (2014). The research analysis of sports industry base. Contemporary Sports Technology.

[7] Breesch, D., Vos, S., \& Scheerder, J. (2014). The financial viability of the fitness industry in belgium. Sport, Business and Management.

[8] Mi-lin, C. (2014). Theory positioning and development research of inner mongolia minority sports cultural industry. Bulletin of Sport Science \& Technology.

[9] Bing-song, Z. (2014). Fitness positive energy: discussion on the character of chinese-style fitness culture industry. Journal of Guangzhou Sport University.

[10] Kai, Y., Hirokazu, A., Tadashi, N., Yujiro, K., Akari, K., \& Kaoru, K., et al. (2014). Relationship between unity and organizational climate in sports teams: examination of the method originating from communication for enhancing team unity. Journal of Japan Society of Sports Industry. 